\title{
GPIC: Quantifying Group Performance in Individual Competitions
}

\author{
Duy Nghia Pham iD \\ Vietnam National University, Hanoi \\ nghiapham@yandex.com
}

26 Jun 2020

\begin{abstract}
In competitions whose prizes are only awarded to individuals, comparing the performance of groups of participants could be problematic. The probability-based GPIC index quantifies group performance considering both the quantity and quality of prizes received.
\end{abstract}

\section{Group Performance Quantification: A Case Study}

Vietnamese National Olympiad is an annual competition organized by the Ministry of Education and Training, Vietnam (MoET) to identify gifted high school students (Le \& Le, 2010). Each year, a total of 71 contest teams nationwide nominate their students to take tests in 12 subjects comprising Mathematics, Informatics, Physics, Chemistry, Biology, Literature, History, Geography, English, French, Russian, and Chinese. Students with good results are awarded individual prizes ranked as first, second, third, and consolation (MoET, 2014). There is no award dedicated to contest teams as a whole, but the team performance is often a topic of interest.

The dataset of awarded students (Pham, 2020) shows that there were 2,381 prizes in Mathematics that have been given from 2010 to 2020. Among that, students from the Nam Dinh team achieved 78 prizes while students from the Nghe An team had 73 prizes. The prize composition of two teams and the whole pool of awardees are given in Table 1. Readers may ask how to compare the performance of two teams. Simply using the total number of prizes will result in that the Nam Dinh team outperformed the Thanh Hoa team whereas only using the number of first prizes indicates that the Thanh Hoa team did better. These commonly used methods, however, ignore the fact that prize categories differ in their importance, but all contribute to the team performance to some extent. Therefore, an index taking into account both the quantity and quality of prizes is necessary to quantify team performance.

This index could be in the form

$$
I=a_{1} x_{1}+a_{2} x_{2}+a_{3} x_{3}+a_{4} x_{4}
$$

where $x_{1}, x_{2}, x_{3}, x_{4}$ are respectively the number of first, second, third, and consolation prizes and $a_{1}, a_{2}$, $a_{3}, a_{4}$ are the weighting factor of these prizes. Given that $a_{1}>a_{2}>a_{3}>a_{4}>0$, better team performance

Table 1: Prize composition and total prize in Mathematics 2010-2020 of Nam Dinh, Thanh Hoa, and all teams.

\begin{tabular}{lrrr}
\hline Prize & Nam Dinh & Thanh Hoa & All Teams \\
\hline First & 3 & 4 & 61 \\
Second & 19 & 22 & 477 \\
Third & 34 & 33 & 836 \\
Consolation & 22 & 14 & 1007 \\
Total & $\mathbf{7 8}$ & $\mathbf{7 3}$ & $\mathbf{2 3 8 1}$ \\
\hline
\end{tabular}


yields higher $I$ value. However, the exact values of the weighing factor remain unknown and need to be reasonably assigned.

\section{Probability-Based Solution}

The prize collection of each team could be thought of as an outcome sampled with replacement from a pool of prizes. The probability of an outcome containing $x_{1}$ first prizes, $x_{2}$ second prizes, $x_{3}$ third prizes, and $x_{4}$ consolation prizes are

$$
P=\left(p_{1}\right)^{x_{1}}\left(p_{2}\right)^{x_{2}}\left(p_{3}\right)^{x_{3}}\left(p_{4}\right)^{x_{4}}
$$

where $p_{1}, p_{2}, p_{3}, p_{4}$ are the proportion of first, second, third, and consolation prizes in the pool such that $p_{1}+p_{2}+p_{3}+p_{4}=1$ and $0<p_{1}<p_{2}<p_{3}<p_{4}$. Better team performance, therefore, yields lower $P$ value.

Expressing $p_{2}, p_{3}, p_{4}$ as power functions of $p_{1}$ which are $p_{2}=\left(p_{1}\right)^{\alpha_{2}}, p_{3}=\left(p_{1}\right)^{\alpha_{3}}, p_{4}=\left(p_{1}\right)^{\alpha_{4}}$ leads to

$$
P=\left(p_{1}\right)^{x_{1}+\alpha_{2} x_{2}+\alpha_{3} x_{3}+\alpha_{4} x_{4}} .
$$

The exponent $I^{\prime}=x_{1}+\alpha_{2} x_{2}+\alpha_{3} x_{3}+\alpha_{4} x_{4}$ follows the general formula of $I$ and the higher $I^{\prime}$ corresponds to the lower $P$. Finally, $I^{\prime}$ can be rewritten

$$
I^{\prime}=x_{1}+\left(\log _{p_{1}} p_{2}\right) x_{2}+\left(\log _{p_{1}} p_{3}\right) x_{3}+\left(\log _{p_{1}} p_{4}\right) x_{4} .
$$

In the example of the Vietnamese National Olympiad in Mathematics 2010-2020, data in Table 1 gives $p_{1}=0.026, p_{2}=0.200, p_{3}=0.351, p_{4}=0.423$. Consequently, $I_{N a m D i n h}^{\prime}=26.214$ and $I_{\text {ThanhHoa }}^{\prime}=26.366$, which suggests that the Thanh Hoa team did outperform the Nam Dinh team.

\section{Generalization}

The index of Group Performance in Individual Competitions (GPIC) has the general formula

$$
G P I C=\sum_{i=1}^{k} x_{i} \log _{p_{1}} p_{i}
$$

where $\mathrm{k}$ is the number of prize categories, $x_{i}$ is the number of prizes in $i^{t h}$ category that the group obtained and $p_{i}$ is the proportion of prizes in $i^{\text {th }}$ category in the pool. Higher GPIC value represents the higher group performance.

GPIC can be extended to other quantification problems as long as the quality of "prize categories" is positively correlated to their rarity.

\section{References}

Le, H. C., \& Le, H. K. (2010, September). Selected Problems of the Vietnamese Mathematical Olympiad (1962-2009) (Vol. 5). WORLD SCIENTIFIC. https://doi.org/10.1142/7514

MoET. (2014). Quy chế thi chọn học sinh giỏi cấp quốc gia. Official Gazette of the Government of Vietnam, 60-91. http://congbao.chinhphu.vn/noi-dung-van-ban-so-22-vbhn-bgddt-12940

Pham, D. N. (2020, April 24). Results of Vietnamese National Olympiads (Version 0.1.0). Zenodo. https: //doi.org/10.5281/ZENODO.3764691 